\title{
A PERSPECTIVA DE GRACILIANO RAMOS SOBRE A DECADÊNCIA DO ROMANCE BRASILEIRO
}

\section{Carlos Alberto Dória}

RESUMO: O artigo discorre sobre as posições de Graciliano Ramos, Otto Maria Carpeaux e Nelson Werneck Sodré dentro do pensamento de esquerda no Brasil e frente ao ciclo do "Romance de 1930", contrastando a heterodoxia de Graciliano e Carpeaux frente aos padrões usuais na crítica de inspiração marxista de então.

PALAVRAS-CHAVE: romance; cultura; dualismo; linguagem; comunismo

\begin{abstract}
The article discusses the positions of Graciliano Ramos, Otto Maria Carpeaux and Nelson Werneck Sodre in the left-wing in Brazil, related to the cycle of "Romance of 1930 " by constrating the heterodoxy of Graciliano and Carpeaux to the usual Standards in the marxism cristicism
\end{abstract}

KEYWORDS: novel; culture; dualism; language; comunism

RÉSUMÉ: L'article discute les positions de Graciliano Ramos, Otto Maria Carpeaux et Nelson Werneck Sodré dans la pensée de gauche au Brésil et concernant au cycle de "Romance de 1930", contrastant l'hétérodoxic de Graciliano et Carpeaux faire face aux modèles habituels dans la critique d'inspiration marxiste, alors en viguer.

MOTS-CLÉ: romance; culture, dualisme; langage; comunisme 
No curto período democrático, após a ditadura Vargas, os comunistas procuram se munir de melhores condições para a intervenção na cena cultural do país. Uma iniciativa foi a edição de uma revista especializada em literatura, com o objetivo de participar dessa esfera da cultura do mesmo modo como participavam da vida política e social em sentido amplo. A revista se dedicou a publicar poemas, cartas, contos; a analisar obras literárias e autores; registrar efemérides; além de acompanhar a movimentação dos intelectuais com vistas à sua auto-organização. Através de alguns poucos ensaios, procurou criar também uma perspectiva analítica para a literatura em seu conjunto ou em abordagens singulares ("literatura para crianças"), esclarecendo relações entre sociedade c representação, entre texto e contexto.

Literatura é a revista que o PCB lança em setembro de 1946, durando até março de 1948, quando surge seu oitavo e último número. Seu diretor responsável foi Astrojildo Pereira, e seu conselho de redação: Álvaro Moreira, Aníbal Machado, Arthur Ramos, Graciliano Ramos, Manuel Bandeira e Orígenes Lessa. Tendo como propósito analisar a concepção que ela expressa sobre o valor da literatura ficcional, eis os principais textos que comentaremos aqui: "A decadência do romance brasileiro", de Graciliano Ramos, aparecido logo no primeiro número; “O pós-modernismo", de Nelson Werneck Sodré, surgido no número seguinte; e "Ulisses", de Otto Maria Carpeaux, publicado no número cinco.

A revista surge com um programa ambicioso. Reconhecendo que "o problema da cultura é na realidade um problema político", quer alinhar a produção cultural com os avanços da democracia e conclama os escritores, filiados a vários partidos políticos ou mesmo apolíticos, a cerrarem fileira e se "aproximarem do povo, e que o povo, por sua vez, sinta que eles são realmente os seus escritores". A literatura como expressão popular corresponde, no dizer da revista, às decorrências que é preciso tirar dos avanços nos domínios da política e da economia, quando a cultura deixa de ser "um problema só de elites para converter-se num problema também de massas", o que abre "novas perspectivas ao trabalho intelectual e cria novas obrigações para os trabalhadores intelectuais". Assim, cerrar fileiras ao lado do povo e contribuir "para a obra de clevação do nível cultural das massas" (LITERATURA, 1946, p. 03) é a conclamação que Literatura lança para todos os intelectuais. 
O tema da dualidade cultural, tão caro aos comunistas, ć cvidente: cultura de massas e cultura de elite. No entanto ele se expressa, no Brasil de então, de duas maneiras. Uma, pela filiação do pensamento de esquerda a uma cultura socialista que tematiza a dualidade como resultado natural da sociedade de classes; outra, que prefere tomá-la a partir da tensão que o Modernismo cria com os estilos anteriores e com o "jacobinismo bocó", para usarmos a expressão de Jorge de Lima. O próprio Astrojildo Pereira, em manuscrito publicado há cerca de uma década (PEREIRA, 1995), buscando separar o joio do trigo e identificar o caminho "progressista" de nossas letras, havia feito uma analise minuciosa da nossa literatura sob a ótica do primeiro dualismo, demorando-se especialmente sobre as ambigüidades de Machado de Assis.

\section{A DUALIDADE DE CULTURAS NA SOCIEDADE BURGUESA E A "DECADÊNCIA"}

Em termos mundiais, ninguém se ocupou com tanto afinco da tese sobre a dualidade de culturas e sua importância para a ficção como Georg Lukács ${ }^{1}$, partindo a sua análise da concepção da história após as agitações revolucionárias européias de 1848 . O aparecimento em cena do proletariado em Paris, o nascimento da Segunda República e a repressão operária que se seguiu, assim como a revolução burguesa nos estados alemães, foram acontecimentos que, para Lukács, provocaram a divisão ideológica de todos os povos em "duas nações", fomentando o desenvolvimento do socialismo e colocando como problema central a questão do progresso e sua condução.

Mas o desenvolvimento do movimento operário, dirá ele, não se deu no vácuo $\mathrm{e}, \mathrm{sim}$, rodeado por todas as ideologias da burguesia decadente, sacudindo as ciências e as artes na exata medida em que o progresso humano apareceu, de modo dramático, como fruto das contradições sociais. Ora, a própria idéia de progresso sofrerá uma "regressão" no pensamento burguês após o abandono da filosofia hegeliana na Alemanha, na medida em que o

1 Ver especialmente as scguintes obras: Lukács, 1968, 1971, 1976 c 1993. 
conceito de contradição cede passo a uma concepção da história como um processo harmonioso de evolução (LUKÁCS, 1983, p. 171-172). É neste cenário, prossegue ele, que veremos avançar a mistificação filosófica da história, o seu trato a partir de uma terminologia pseudocientífica, a emergência do tema das raças como uma entidade mítica e anti-histórica - enfim, o surgimento daquelas formas que correspondem à própria decadência do pensamento burguês, antes revolucionário.

Ora, se investigarmos a trajetória do termo "decadência" veremos que ele teve, na Alemanha do século XIX e XX, um duplo tratamento. Por um lado, temos Marx que o utilizou no sentido ordinário expresso pela palavra verfall [decadência, declínio]; por outro, Lukács utilizou a palavra dekadenze, com a conotação francesa de "décadence", referente ao movimento estético de Gautier e Bodelaire sob o simbolismo fin de siècle. Como termo negativo, esta visão foi popularizada por Max Nordau em sua novela de 1892, Entartıng, aproximando a degeneração biológica à social quando descreve a vanguarda como "uma doença mental da nação".

Os argumentos de Lukács, baseados na tese de que a burguesia européia entrou em declínio após o fracasso das revoluções de 1848, nos oferecem uma visão tradicionalista de declínio estético, ao mesmo tempo em que conferem respeitabilidade intelectual a uma fórmula do marxismo vulgar quando se expressa em termos de "burguesia decadente". Dessa perspectiva, Lukács é arrebatado pela idéia de previsão do desenvolvimento estético coisa que se mostrou bastante imprópria, ao identificar o ápice do romance burguês em Thomas Mann e a sua decadência em James Joyce, contrapondo-os à estética socialista nascente, conforme viu de modo promissor em Iliá Eremburg. Ao inscrever uma finalidade na literatura - o expressar uma cultura popular -, os comunistas como Lukács cometeram enormes erros de juízo estético e político.

No geral, a teoria do romance de Lukács supõe uma profunda aderência entre a criação literária e os tipos sociais engendrados pela sociedade burguesa, a tal ponto que denominou o romance "epopéia burguesa" e analisou uma infinidade de obras segundo um critério de graus de exaurimento da representação da sociedade $\mathrm{cm}$ que estavam inseridas. Certas obras e certos 
autores (Balzac e Flaubert, especialmente) foram consideradas como "expressão máxima" a que poderia chegar a estética burguesa cm suas épocas. Após atingir o pináculo, o romance decai. $\mathrm{O}$ suposto desta teoria do romance é que uma arte proletária, em formação, seria superior ao romance burguês, pois só o socialismo poderia elevar a consciência estética da humanidade. Para ele, tais concepções sc apóiam em filosofias da história, acompanhando a evolução de toda a sociedade, sendo necessário ao crítico literário sempre se perguntar se a civilização moderna "segue para cima ou para baixo" (LUKÁCS, 1983 , p. 11).

Mas Lukács também nos oferece um segundo e mais fértil ponto de vista para os fenômenos da cultura em sua Nova bistória da literatura alemã. Nessa obra, ele analisa como a cultura alemã absorve as diretrizes do Iluminismo c como, posteriormente, ela se configura na era do imperialismo. Para esses dois períodos, a diretriz é compreender a base social que constitui "a causa eficaz das tendências e dos fenômenos literários", isto é, aquilo que permite posicionar a "grande literatura" para além dos dualismos sociais e estéticos, surpreendendo o seu papel de precursora da verdadeira democracia (LUKÁCS, 1971, p. 113).

O ponto de partida da análise do primeiro tema - o Iluminismo - é, na Alemanha, a ausência de povo, de público, de nação e de arte poética que possam ser identificados como "autênticos", conforme análise de Herder em 1777. Assim, o programa literário ć criar "habilmente um passado orgânico do povo alemão, da cultura e da literatura alemã, e conferir-lhe um caráter fidedígno. Esta ânsia espasmódica prevalece durante o romantismo e se acentua na Alemanha prussiana com a reação e os planos de domínio mundial. Certamente os escritores lúcidos $\mathrm{c}$ honestos com freqüência resistem a este tipo de construção orgânica, mas na maioria dos casos não exercem influência decisiva. Goethe lutou constantemente contra esta tendência romântica". Lukács segue analisando como, em outros países, o surgimento da burguesia se estabelece como premissa da criação c consolidação da unidade nacional, ainda que provisoriamente possa pactuar com a monarquia absoluta, como se vê $\mathrm{em}$ Shakespeare em relação aos Tudor, ou Voltaire em relação a Luis XIV. Na Alemanha, ao contrário, "só é possível a ficção enganosa de uma 
concordância entre os poderes reinantes e a cultura alemã, e pela mesma razão ela implica sempre num certo matiz de mendicância. Esta mentira, que com grande freqüência nasce do auto-engano, envenena a totalidade da história, cultura e literária da Alemanha". Desse modo, a grandeza e limite da literatura alemã estão dados pelos contrastes com o regime imperante; e ela é grande porque compreende o problema vital do povo alemão, aprofundando esse contraste, e é débil na medida em que o contraste com a estrutura socialestatal alemã é "o principal fator que determina o caráter idealista da cultura e da literatura alemã” (LUKÁCS, 1971, p. 15).

A “alegre falsificação do passado", os modos de apropriação da arte do grand siècle francês, a recepção da literatura inglesa - tudo passa por um amesquinhamento cuja origem é a subordinação ideológica da mediocridade pequeno-burguesa ao absolutismo feudal. Esta a razão do "rebaixamento" do Iluminismo na Alemanha. Em conseqüência, projeta-se a figura do intelectual pequeno-burgues que ocupa posições subordinadas na burocracia estatal o que lhe confere uma certa independência econômica a par com uma limitação de horizontes - além daqueles que vivem $\mathrm{em}$ algumas cortes isoladas, protegidos pelo mecenato; ambos concorrendo para a elaboração de uma literatura que reflete a dignidade pessoal do escritor, ou a "missão social e nacional do escritor independente". Assim, o desenvolvimento do Iluminismo confunde-se com essa forma de luta de libertação "apartada da esfera imediatamente social", projetando-se como construção subjetiva, lírica, como antecipação profética e genial das tarefas da Revolução que ainda não ocorreu na Europa e que, em contraste com a realidade alemã, aparece como uma deformação submetida por ela. Desse modo, temos que "o tipo de iluminista médio", tão comum na França c na Inglaterra, é uma notável raridade na Alemanha.

Ora, neste quadro, diz Lukács, "quanto mais ardente e apaixonada a luta dos iluministas alemães contra a ideologia das cortes, tanto mais claramente percebem que esta concepção do mundo aristocrática e cínica é hostil, e definitivamente não podem distinguir os originais democráticos franceses e ingleses na sua caricatura germano-cortesã” (LUKÁCS, 1971, p. 15). O interessante nesta perspectiva de Lukács é como as idéias do Iluminismo se 
transformam para se adequar à realidade sócio-política alemã, criando formas verdadeiramente novas de expressão que se afastam de um enquadramento "realista" para se constituirem numa cultura sem eficácia política, onde é forte o componente subjetivo e idealista.

\section{VISÃO BRASILEIRA DA DUALIDADE CULTURAL}

Se olharmos o conjunto dos oito números de Literatura, o modelo de "escritor do povo" é Lima Barreto, conforme elogio fúnebre escrito por Lucia Miguel Pereira (1946, p. 03-32). E também Castro Alves, a julgar pelo manifesto surgido em seu centenário, assinado por centenas de intelectuais $\mathrm{e}$ apresentado como editorial da revista. Trata-se de autores que encarnam um ideal segundo o qual esse personagem - o escritor - deva se afastar de tudo o que "signifique passatempo, divertimento, jogo, esporte, luxo, bibelô bibliográfico" (LITERATURA, 1947). A literatura é terreno de tomada de consciência.

O texto mais próximo dessa concepção, dentre os apontados, é o de Nelson Werneck Sodré. Para ele, a "agitação modernista [foi] mais fecunda pelo que denunciou do que pelo que trouxe em si mesma" (SODRÉ, 1946, p. 04). Isso porque, mais cedo do que a própria Revolução [1930], o movimento modemista "descarncterizou-se, multiplicando-se em correntes mirins as mais variadas e até contrastantes". O seu sentido foi de preparação do advento do que o autor chama de "post-modernismo", ou "grande impulso renovador" que se seguiu ao modernismo de 1922. Seu principal beneficio foi fixar o romance como "gênero normal para tradução literária dos problemas humanos" que teve, como marca íntima, "revestir-se de um caráter nacional e popular" (SODRÉ, 1946, p. 06). Werneck frisa isso porque, the parece, um dos aspectos mais esquecidos da crítica e da história literária tem sido a "correspondência entre a tarefa de criação c o público", sendo que o período é marcado por uma "sucessão de romances dignos de atenção", isto é, que superam o artificialismo da fase anterior, inclusive o naturalismo, que se assemelhava aos panos de boca teatrais "ou aos cenários pintados dos fundos de palco". 
Sua análise caminha no sentido de mostrar como os acontecimentos de 1930 envolveram um número crescente de atores políticos, adquiriram dimensão popular, romperam barreiras de classe, inclusive os limites da fruição cultural, de tal sorte que "o grande segredo, e a força mesma do romance, depois de 1930, consistiu efetivamente na transferência ao plano da ficção dos grandes problemas coletivos que agitavam o país, ou que haviam motivado, na tradição, pela herança, tais problemas. Nesse sentido é interessante notar como o romance brasileiro do surto posterior a 1930 não revelou personagens, não se demorou em recortá-las. A crítica à ficção francesa, que servira de modelo ao romance brasileiro esporádico e anêmico anterior ao impulso modernista, frisara a capacidade para o gênero no condão de criar tipos". E, de modo taxativo, conclui que "uma literatura só pode aparecer com os seus contornos bem precisos, com fisionomia autônoma, quando se liga ao que há de peculiar na gente e na época em que se desenvolve" (SODRÉ, 1946, p. 10-11).

Este texto de Werneck Sodré reproduz, assim, os argumentos lukácsianos que tendem a ver a ficção nos marcos do espelhismo social, isto é, como uma representação das contradições sociais ou dualidade de culturas. O "nacional e popular" é o eixo de gravitação da cultura inovadora, deixando para trás o francesismo como modelo que cheira impostação. Não há, dessa perspectiva de Werneck Sodré, um esforço para mergulhar no romance e sua construção, isto é, procurar desvendá-lo como um fenômeno da linguagem. O romance é, por definição, antes de tudo social, e Werneck Sodré está se referindo especialmente ao "romance de 30 ". Esse "interesse pelo Brasil", a valorização do romance, repercute também no ensaismo e na crítica literária. Para Sodré, houve um impulso extraordinário do ensaismo e a oportunidade criada pelo novo quadro político permitiu "retomar, em relação a um movimento tão efetivo como o do post-modernismo, processos de crítica operantes e seguros, dignos de servir à historiografia literária, gênero este tão mal posto, depois da morte de Silvio Romero" (SODRÉ, 1946, p. 12).

Numa direção diversa dessa, onde a crítica literária se confunde com a crítica historiográfica, situa-se o texto de Otto Maria Carpeaux sobre Ulisses de James Joyce. O autor austríaco não desconhece a "análise lukácsiana". Conforme lembra, todos reconhecem em Ulisses uma obra excepcional, mas 
"apenas não concordam quanto às conclusões históricas: alguns consideram a obra como o maior romance de todos os tempos, cume e suma do gênero; outros reconhecem em Ulisses a paródia definitiva do gênero, e lembram-se do aforismo de Kicrkegaard segundo o qual 'toda fase histórica termina com a paródia de si mesma', proclamam o romance de James Joyce como ponto final da história do romance, desse gênero típico da burguesia". Contra essa concepção classista do romance, Carpeaux desenvolverá a análise centrada na apropriação da língua inglesa por James Joyce, na metaforização do Ulisses de Homero, em concepções de linguagem do inconsciente, entendendo o romance não como "um defeito mental do autor e, sim, [como] o resultado do seu método literário” (CARPEAUX, 1947, p. 09).

Para Carpeaux, a língua se desenvolve, nos tempos modernos, tendo em conta a capacidade intelectual do leitor e, dessa perspectiva, "a Babel de Joyce é uma paródia enorme da língua, ou antes de todas as línguas: da falada, da escrita e da sonhada. $\mathrm{Na}$ literatura de todos os tempos não parece existir nada de igual ou comparável". Esse Ulisses moderno "não voltará nunca para Itaca, porque Itaca já não existe. Desentendeu-se definitivamente com os homens, ao ponto de não ser mais entendido por cles. Daí a língua particular, a incomunicabilidade" (CARPEAUX, 1947, p. 17).

Nessa análise - que não paga tributo ao historicismo analítico de Lukács, particularmente à idéia de "decadência" - a "incomunicabilidade" de Ulisses erige-se em correspondência com a modernidade, sem ser expressão de degeneração de qualquer pensamento. Em outras palavras, a dificuldade de Lukács na datação da criatividade literária só se explica porque o crítico está munido de um aparato interpretativo onde as classes determinam a literatura, subsumida que está no dualismo capitalista, sem reconhecer a autonomia da linguagem. Assim, não deixa de ser notável que Literatura haja acolhido uma crítica literária divergente com os modos comunistas de então fazê-la mas coerente com o seu programa pluralista.

Já Graciliano Ramos, distingue-se tanto de Werneck Sodré quanto de Carpeaux. A "Decadência do romance brasileiro" é texto centrado no "romance de 30", nos "representantes máximos do romance nordestino" do qual, reconhecemos, é ele mesmo expoente. Mas Graciliano não se demorando 
sobre as condições políticas da sua emergência, preferindo analisar a linguagem expressa em vários romances dessa fornada. Ele, como sabemos, tem como preocupação central a construção da linguagem narrativa; várias vezes recorreu, em sua obra, à "metáfora do papagaio" como expressão do linguajar inútil, dissimulador, alienado, desprovido de conteúdo: "narrativa idiota, conversa de papagaios" (RAMOS, 1975, p. 195). O valor da narrativa está em se afastar desse paradigma.

Ora, para ele, os autores do romance nordestino da geração de 1930 eram "observadores honestos, bons narradores", mas se atentarmos para o conjunto da obra, "perceberemos nela uma curva. Fizeram, quase sem aprendizagem, ótimas histórias, com tanta sofreguidão que pareciam recear esgotar-se. Não se esgotaram talvez, mas estancaram, como se tivessem perdido o fôlego, ou publicaram trabalhos inferiores aos primeiros. E convêm notar que essa queda se deu quando cessou a agitação produzida pela revolução de Outubro. Subiram até 1935. Ai veio a decadência” (RAMOS, 1946, p. 21).

O autor acompanha o argumento de Werneck Sodré de que os modernistas não construíram, mas "usaram a picareta e espalharam o terror entre os conselheiros". Foi quando surgiram desconhecidos que se afastaram "dos preceitos rudimentares da nobre arte da escrita" e, embrenhando-se pela sociologia e pela economia, "lançaram-se no mercado $\mathrm{em}$ horrorosas edições provincianas, romances causadores de enxaqueca ao mais tolerante dos gramáticos". Mas, com se sabe, "as barbaridades foram aceitas, lidas, relidas, multiplicadas, traduzidas e aduladas". Graciliano se refere especialmente às obras de Raquel de Queiroz, Jorge Amado, José Lins do Rego, Amando Fontes.

No seu entender, Raquel de Queiroz, que escreveu O quinze cm 1930 com apenas 18 anos, têm passagens notáveis. Em João Miguel, romance de 1932, os personagens "conversam direito sem consultar o dicionário"; já Caminhso de Pedra, de 1936, é "livro demagógico" e "quase sempre intencional e frio". Em 1937, outro autor, José Lins do Rego, depois de "cinco romances muito sérios", nos deu Pureza, que é "um salto para baixo. Em 1938, com Pedra Bonita, desceu novo degrau".

Igualmente sintética é sua análise de Jorge Amado, que "começou com O país do carnaval, na adolescência. Cacau, em 1932, ainda hesitante, já revela o escritor que adquiriu celebridade em pouco tempo, nestas paragens e em 
lugares cultos. Surr, coleção de tipos magnífica, veio cm 1933. Com Jubiabá, em 1935, chega o romancista ao ponto mais elevado. Existe ai uma sentinela de defuntos, das melhores coisas que nos deu. Mar morto, de 1936, é um recuo[...] está longe de Jubiába. A poesia que há nesse muda-se em toada agradável ao ouvido, e certos estribilhos ("É doce morrer no mar") dizem o contrário do que o autor pretende sustentar. Capitães da areia, publicado em 1937, não vale Mar morto" (RAMOS, 1946, p. 22).

Ora, o critério de decadência de Graciliano Ramos é um critério estritamente literário, isto ć, adstrito à linguagem. Na análise de Amando Fontes, comenta Rua da Siriri (1937) e ressalta o aspecto de novela "certinha, conveniente", porque os personagens do prostibulo são rigorosamente policiados "na sintaxe e na moral" de modo que, "se os lupanares fossem aquilo, venceriam, $\mathrm{cm}$ austeridade, $\mathrm{em}$ recato, os mais inflexíveis cstabelecimentos de educação feminina". Desse modo, as mulheres de Amando Fontes "representam bem os nossos romances atuais, direitos, comedidos, inofensivos"; neles baniu-se o palavrão, afastou-se o negro, as personagens branquearam "e, timidamente, aproximam-se da Academia".

Ora, essa trajetória, reconhece Graciliano, ć reforçada também pela crítica, para a qual existem dois gêneros de romances: os urbanos, que são os bons; os rurais, que são os ordinários. Assim, a crítica conspira contra o antigo "romance nordestino". "O que se tem feito é secundário, chinfrim. Não vale a pena falar em mocambos, bagaceiras, cadeias, negros do cais. Insignificâncias. É necessário apresentarmos ao público sutilczas e complicações, as que existem no casino da Urca e nos banhos de Copacabana" (RAMOS, 1946, p. 23).

A essa demanda do mercado, adaptaram-se os melhores romancistas, outrora provincianos $\mathrm{e}$ isentos de ambições, quando contaram o que viram, o que ouviram, sem imaginar o sucesso. Contudo, "subiram muito - e devem sentir-se vexados por terem sido tão sinceros. Não voltarão a tratar daquelas coisas simples. Não poderiam recordá-las. Estão, longe delas, constrangidos, limitados por numerosas conveniências. Para bem dizer, estão amarrados. Certamente ninguém thes vai mandar que escrevam de uma forma ou de outra. Ou que não escrevam. Não senhor. Podem manifestar-se. Mas não se manifestam. Não conseguem recobrar a pureza e a coragem primitivas. Transformaram-se. Foram transformados. Sabem que a linguagem que 
adotaram não convêm. Calam-se. Não tinham nenhuma disciplina, nem na gramática nem na política. Diziam às vezes coisas absurdas - e excelentes. Já não fazem isso. Pensam no que é necessário dizer. No que é vantajoso dizer. No que é possivel dizer" (RAMOS, 1946, p. 24).

A decadência do romance brasileiro - do "romance nordestino" ou "Romance de 1930" scria mais exato - assemelha-se, portanto a uma traição. Não uma "traição de classe" ou coisa do gênero, mas a uma traição da linguagem por conveniências que se impuseram como nova necessidade para escritores cooptados por conta do sucesso que fizeram ao romper com os cânones da velha ordem literária. $O$ romance aparece então como uma imbricação complexa entre personagens, gramática, valores c assim por diante - uma conformação da linguagem que se apropria de modos específicos da realidade. Nesse sentido, Graciliano nos sugere um caminho fértil para se analisar a incrustação da linguagem, do estilo, numa dada sociedade.

Como já procuramos demonstrar em outro lugar, a grande divisão política do Brasil, para Graciliano Ramos, é aquela que, sob todos os aspectos, hierarquiza as regiões, criando uma oposição dialética entre o Nordeste e o país como um todo (DÓRIA, 1993, p. 19-34). É como se visse de um modo muito particular aquela oposição abstrata entre as "duas culturas" de que fala Luckács.

Ao se referir à sua Palmeiras dos Índios, registra que é uma "cidade essencialmente brasileira [...] Reproduz-se entre nós, $\mathrm{cm}$ ponto pequeno, o que o país em ponto grande produz" (RAMOS, 1975, p. 60). Nessa sua posição, reiterada várias vezes ("o que o Rio de Janeiro imita cm grosso nós imitamos a retalho"), há a clara consciência da unidade nacional, o que o distingue de outros analistas do Nordeste que insistem em representar a região contraposta à nação, reivindicando por isso uma melhor posição no cenário político e na economia nacional (DÓRIA, 2007, p. 19-34). Para Graciliano não se trata disso: a região não é algo marginal a ser incorporado; é parte constitutiva da nação através das suas diferenças, isto é, a sua posição relativa é que expressa as contradições do todo. Nesse sentido preciso, a nação é anterior ao próprio recorte regional.

Nesse contexto, o grande mérito que via no "romance de 30 " era o rompimento com a representação folclorizada da região, visão até então 
dominante que reforçava a percepção dessa parte do país como se fosse um "outro". $\mathrm{O}$ "romance de 30" se opõe, por exemplo, à chamada "Literatura do Norte", representada por autores como Franklin Távora, Gustavo Barroso e outros que, por produzirem uma literatura de dissimulação dos problemas regionais ao apresentá-los como "folclóricos", encontram no Rio de Janeiro uma audiência que só reforçava esta forma de exclusão cultural, pois não há porque romper com ela, visto que se apresentam como uma espécie de "crônica" de uma vida diferente.

Dai a radicalidade da nova linguagem do "romance de 30 " é tão importante, o ponto essencial da revolução cultural que trazia como promessa: "os inimigos da vida torcem o nariz e fecham os olhos diante da narrativa crua, da expressão áspera. Querem que sc fabrique nos romances um mundo diferente deste, uma confusa humanidade só de almas[...]. Põem essas almas longe da terra, soltas no espaço. Um espiritismo literário, excelente como tapeação" (RAMOS, 1975, p. 135).

Concretamente, o que Graciliano Ramos nos mostra em "Decadência do romance brasileiro" é que o "romance de 30 " oscilou entre as duas modalidades de representação regional em literatura; mostrou, de um lado, as fissuras sociais do Nordeste e, de outro, acomodou-se, realinhou-se com a estética da ordem. Neste sentido é que ele pôde criticar os seus companheiros de letras - muitos deles também companheiros de partido - indicando uma espécie de "traição" a um programa generoso de criação de uma nova linguagem e uma nova cultura.

Ele mesmo, sabemos, nunca se deixou contaminar por esse espírito e, daí, a sua autoridade incontestável de crítico. Mas não deixa de ser intrigante para o analista de hoje que ele tenha escrito Vidas Secas - seu texto mais percuciente - em 1937, já no período que denominou de "decadência". Depois desse ano, nunca mais produziu uma novela sequer - limitando-se a crônicas, memorialística e estórias infantis. Parecia sentir-se pessoalmente traido no entusiasmo de produtor de uma nova cultura. A decadência do romance confunde-se com a decadência do seu entusiasmo criador.

? Recordemos aqui o título do livro clássico: "O outro Nordeste" (MENEZES, 1970). 


\section{REFERÊNCIAS BIBLIOGRÁFICAS}

CARPEAUX, Otto Maria, “Ulisses”, Literatura, n. 5, 1947

DÓRIA, Carlos Alberto, "Graciliano e o paradigma do papagaio", Revista do Instituto de Estudos Brasileiros, São Paulo, n. 35: 19-34, 1993

"O Nordeste: problema nacional para a esquerda", in MORAES, João Quartim e DEL ROIO, Marcos, História do marxismo no Brasil, vol. 4, Campinas, Editora da Unicamp, 2007

LUKÁCS, Georg, La théorie du roman (1920), Paris, Éditions Denoël, 1968 1971 . Nueva bistoria de la literatura alemana, Buenos Aires, La Pléyade, . Saggi Sul Realismo, Torino, Einaudi, 1976 . The bistorical novel, Lincon, University of Nebraska Press, 1983 . German realists in the nineteenth century, Cambridge, MIT Press, 1993 MENEZES, Djacir. O outro nordeste. Rio de Janeiro: Artenova, 1970.

PEREIRA, Astrojildo, "Documento", Idéias - Revista do Instituto de Filosofia e Ciências Humanas, ano 2, vol. 1, Campinas, janeiro/julho 1995

PEREIRA, Lucia Miguel, "Um Escritor do Povo”, Literatura, n. 3, 1946

RAMOS, Graciliano, "Decadência do romance brasileiro", Literatura, n. 1, 1946

. Linhas tortas, Rio de Janeiro, Record, 1975

SODRÉ, Nelson Werneck, "O póst-modernismo", Literatura, n. 2, 1946

\section{OUTRAS REFERÊNCIAS}

LITERATURA, “Apresentação”, ano I, n. 1, Rio de Janeiro, set, 1946 LITERATURA, “Apresentação”, ano I, n. 4, Rio de Janeiro, jan-jun, 1 